\title{
A preliminary evaluation of surface latent heat flux as an earthquake precursor
}

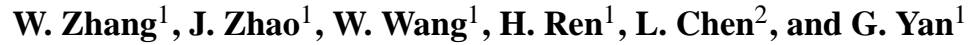 \\ ${ }^{1}$ State Key Laboratory of Remote Sensing Science, School of Geography, Beijing Normal University, Beijing 100875, China \\ ${ }^{2}$ College of Forestry, Beijing Forestry University, Beijing 100083, China
}

Correspondence to: J. Zhao (201131170021@mail.bnu.edu.cn)

Received: 16 January 2013 - Published in Nat. Hazards Earth Syst. Sci. Discuss.: 13 June 2013

Revised: 9 September 2013 - Accepted: 10 September 2013 - Published: 22 October 2013

\begin{abstract}
The relationship between variations in surface latent heat flux (SLHF) and marine earthquakes has been a popular subject of recent seismological studies. So far, there are two key problems: how to identify the abnormal SLHF variations from complicated background signals, and how to ensure that the anomaly results from an earthquake. In this paper, we proposed four adjustable parameters for identification, classified the relationship and analyzed SLHF changes several months before six marine earthquakes by employing daily SLHF data. Additionally, we also quantitatively evaluate the long-term relationship between earthquakes and SLHF anomalies for the six study areas over a $20 \mathrm{yr}$ period preceding each earthquake. The results suggest the following: (1) before the South Sandwich Islands, Papua, Samoa and Haiti earthquakes, the SLHF variations above their individual background levels have relatively low amplitudes and are difficult to be considered as precursory anomalies; (2) after removing the clustering effect, most of the anomalies prior to these six earthquakes are not temporally related to any earthquake in each study area in time sequence; (3) for each case, apart from Haiti, more than half of the studied earthquakes, which were moderate and even devastating earthquakes (larger than $M_{\mathrm{w}}=5.3$ ), had no precursory variations in SLHF; and (4) the correlation between SLHF and seismic activity depends largely on data accuracy and parameter settings. Before any application of SLHF data on earthquake prediction, we suggest that anomaly-identifying standards should be established based on long-term regional analysis to eliminate subjectivity. Furthermore, other factors that may result in SLHF variations should also be carefully considered.
\end{abstract}

\section{Introduction}

Among a large number of so-called earthquake precursors (such as geomagnetism, gas composition and electromagnetic radiation), thermal variations have been of particular interest in the last several decades. In the earlier 1980s, temperature data obtained from ground meteorological stations were used to study the relationship between earthquakes and soil or air temperature changes at different depths and elevations (Hao et al., 1982; Wang and Zhu, 1984). In recent years, the development of satellite and sensor technologies has allowed observation at much higher spatial and temporal resolutions. By using NOAA AVHRR satellite thermal images, Tronin used thermal remote sensing data to observe abnormal infrared radiation in a seismically active region in central Asia (Tronin, 1996). Analogous remotely sensed images were also used in Russia, China, India, Mexico and other countries (Choudhury et al., 2006; Genzano et al., 2007; Ouzounov and Freund, 2004; Ouzounov et al., 2007; Pulinets et al., 2006; Qiang et al., 1997; Tronin, 2000). Furthermore, thermal remote sensing products have also been employed in the study of the relationship between thermal variations and seismic activity, such as outgoing longwave radiation (OLR) and temperature of a black body (TBB) (Ouzounov et al., 2007; Zhang et al., 2010).

As a key component of Earth's energy budget, SLHF (surface latent heat flux), which represents the heat flux resulting from changes in water phase, has been recently proposed as a possible precursor to marine/coastal earthquakes. Dey and Singh firstly found some anomalous SLHF peaks a few days prior to five earthquakes that occurred near the ocean, causing them to propose SLHF as a precursor to seismic activity 


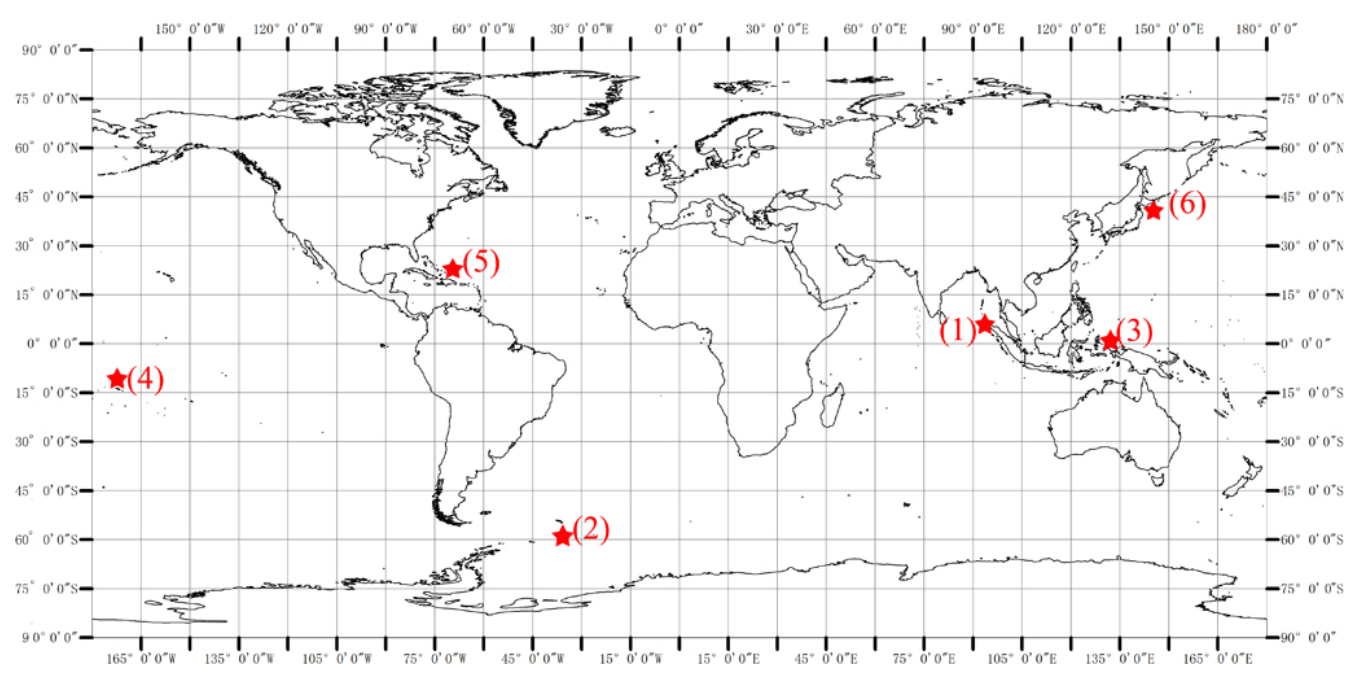

Fig. 1. Locations of studied earthquakes.

in coastal regions (Dey and Singh, 2003). Based on their discovery, although some data-mining technologies including wavelet transformation and spatiotemporal continuity analysis have been consequently introduced to explore the temporal and spatial variations of SLHF before and after earthquakes (Cervone et al., 2004, 2005; Singh et al., 2007), there are quite a few of scientists still focusing on point and shortterm analysis. Most of the present study of relationships between seismic activity and SLHF precursors generally consists of focusing on one or more specific earthquakes, comparing their individual daily SLHF for several months before the earthquake to background values (calculated differently by different authors), declaring anomalies, displaying several images of the variation in SLHF prior to and following the earthquake, and analyzing the spatial patterns of SLHF variations in a certain area (Chen et al., 2006; Dey and Singh, 2003; Li et al., 2008; Pulinets et al., 2006; Qin et al., 2010, 2008).

As a potential earthquake precursor, SLHF variation is urged to be evaluated statistically. Although many scientists have studied the theory of pre-seismic thermal variations (Freund et al., 2007; Pulinets et al., 2006; Saraf et al., 2009), there is still no comprehensive and widely accepted geophysical explanation for thermal changes prior to seismic activity. To get rid of false predictions caused by random noise or by chance coincidence, any earthquake-predicting method (whether short-term or long-term) needs to be evaluated statistically (Kagan, 1997; Geller, 1997). Kagan and Jackson proposed a set of rules for evaluating earthquake forecasting methods during the famous VAN debate (Jackson, 1996; Kagan and Jackson, 1996). According to their research, any possible earthquake-predicting method should satisfy two basic standards: (1) that the suitability of the method be ascertained and values of adjustable parameters be established during the learning period; and (2) that no parameter fitting is allowed in the control stage. So far, there is hardly any published paper focusing on the evaluation of the so-called earthquake precursor SLHF variation.

In this study, the evaluation procedure was carried out in three steps: identifying short-term anomalies based on other studies, determining if they are earthquake-induced anomalies using long-term data, and changing some parameters to analyze their effect on the correlation foundation. As a result, this paper is organized as follows: earthquakes and SLHF products are introduced in Sect. 2; the quantitative short- and long-term relationships are illustrated, classified and evaluated in Sect. 3; the discussion is extended to SLHF data and related parameters to address the importance of data applicability and threshold settings in Sect. 4; and concluding remarks are given in Sect. 5.

\section{Data description}

\subsection{Earthquakes}

During the past decade, dozens of disastrous earthquakes occurred in close proximity to an ocean or below the seafloor. In this paper, we take six earthquakes into consideration: Sumatra, Papua, Samoa, Haiti, Tohoku and one east of the South Sandwich Islands (hereafter referred to as ESSI). The main selection criteria include a magnitude of $M_{\mathrm{w}}=7.0$ or larger, similar focal depth in the crust and near or beneath an ocean. Figure 1 shows the epicentral locations of the selected earthquakes, and Table 1 gives their basic information (http://earthquake.usgs.gov/).

\subsection{Surface latent heat flux data}

Earth's surface not only absorbs and releases heat by electromagnetic radiation but also exchanges energy with the 
Table 1. Basic information of studied earthquakes.

\begin{tabular}{lllrrr}
\hline Name & $\begin{array}{l}\text { Time } \\
\text { (UTC) }\end{array}$ & $\begin{array}{l}\text { Location } \\
\text { (Lon/Lat) }\end{array}$ & $\begin{array}{r}\text { Magnitude } \\
\left(M_{\mathrm{W}}\right)\end{array}$ & $\begin{array}{r}\text { Depth } \\
(\text { Lon } / \text { Lat })\end{array}$ & NCEP grid \\
\hline Sumatra (1) & $2004 / 12 / 26,00: 58$ & $95.982^{\circ} \mathrm{E}, 3.295^{\circ} \mathrm{N}$ & 9.0 & 30 & 51,49 \\
ESSI (2) & $2006 / 01 / 02,06: 10$ & $21.606^{\circ} \mathrm{W}, 60.957^{\circ} \mathrm{S}$ & 7.4 & 13 & 107,15 \\
Papua (3) & $2009 / 01 / 03,19: 43$ & $132.885^{\circ} \mathrm{E}, 0.414^{\circ} \mathrm{S}$ & 7.7 & 17 & 70,47 \\
Samoa (4) & $2009 / 09 / 29,17: 48$ & $172.095^{\circ} \mathrm{W}, 15.489^{\circ} \mathrm{S}$ & 8.1 & 18 & 187,39 \\
Haiti (5) & $2010 / 01 / 12,21: 53$ & $72.571^{\circ} \mathrm{W}, 18.443^{\circ} \mathrm{N}$ & 7.0 & 13 & 134,57 \\
Tohoku (6) & $2011 / 03 / 11,05: 46$ & $142.369^{\circ} \mathrm{E}, 38.322^{\circ} \mathrm{N}$ & 9.0 & 32 & 76,67 \\
\hline
\end{tabular}

atmosphere through sensible and latent heat exchange. The former is caused by air turbulence or convection, and the latter is mainly caused by water phase changes. The term "surface latent heat flux" is used to describe the flux of heat from the surface of the land or ocean to the atmosphere that is associated with the solidification, melting and transpiration of water (Bourras, 2006; Schulz et al., 1997). Due to the homogeneity of ocean medium, SLHF can be easily used to monitor heat variations at the ocean-atmosphere interface.

SLHF data can be obtained in various ways. Traditionally, SLHF has been computed from bulk formulas that use ship- or ground-based measurements. However, due to the low temporal and spatial resolution of this point-type data, the availability and accuracy of station-derived fluxes are relatively limited (Singh et al., 2001). By assimilating land surface, ship, rawinsonde, pibal, aircraft, remote sensing data and other available data, the NCEP/NCAR (National Centers for Environmental Prediction/National Center for Atmospheric Research) reanalysis system provides global integrated reanalysis data series at an accuracy of $10-30 \mathrm{~W} \mathrm{~m}^{-2}$, suitable for long-term surveys (1979 and newer data - the third phase of the evolution of the global observing system, i.e., the "modern satellite era"). The data employed in this paper were downloaded from the FTP server ftp://ftp.cdc.noaa. gov. Daily mean SLHF data are represented by a Gaussian grid of 94 lines from $88.542^{\circ} \mathrm{S}$ to $88.542^{\circ} \mathrm{N}$, with regular $1.875^{\circ}$ longitudinal spacing and projected onto a rectangular grid (Kalnay et al., 1996; Kistler et al., 2001). Corresponding NCEP grid values can be calculated from the longitude and latitude of individual earthquake epicenters (refer the last column in Table 1).

\section{Method}

\subsection{Classification of relationship}

To evaluate the correlation between earthquakes and SLHF anomalies statistically, we assumed their behaviors to be two independent events and classified their relationships into four categories: 00, 01, 10 and 11 (see Table 2). To our concerns, only anomalies that occurred within a specified time window before a given earthquake were considered. The definition
Table 2. Four categories of the relationship between earthquake and anomaly.

\begin{tabular}{lrr}
\hline No. & Earthquake & Anomaly \\
\hline 00 & - & - \\
01 & - & $\sqrt{ }$ \\
10 & $\sqrt{ }$ & - \\
11 & $\sqrt{ }$ & $\sqrt{ }$ \\
\hline
\end{tabular}

of "anomaly" as well as "time window" will be given in Sect. 3.2.

Figure 2 shows the four types of relationships in the area of the Tohoku earthquake over a period of more than $20 \mathrm{yr}$. DOT stands for "day of total years", which spans from 1 January $1991($ DOT $=1)$ to 1 January $2012($ DOT $=4383)$. Dark triangles mark values that surpass the anomaly threshold, which could be interpreted as anomalous signals. The arrows indicate specific earthquakes during the study period. As the 00 category indicates a period of no seismicity or anomalies, only categories 01,10 and 11 are discussed in the following sections.

\subsection{Establishment of parameters}

To define the thermal anomaly precisely, we firstly selected four adjustable parameters before the formal evaluating procedure: (1) $M-$ an earthquake with a magnitude $M\left(M_{\mathrm{w}}\right)$ or larger is included in the earthquake list and is considered for correlation examination; (2) anomaly threshold - values beyond this threshold are considered as anomalies; (3) time window - the length of days between the beginning of an anomaly and an earthquake; and (4) $E$ - the extent/amplitude of an anomalous value. For SLHF data, the unit of $E$ is $\mathrm{W} \mathrm{m}^{-2}$.

Secondly, for all of these earthquakes, the values of former two parameters were preliminarily fixed according to previous researches. A comprehensive review of the literature on the identification of thermal anomalies, coupled with knowledge of seismology and statistics, suggests that (1) the parameter $M$ can be set at a magnitude of 5.0, which is a moderately sized earthquake; and (2) the anomaly threshold can be defined as the mean value of SLHF data over tens of 
(a)

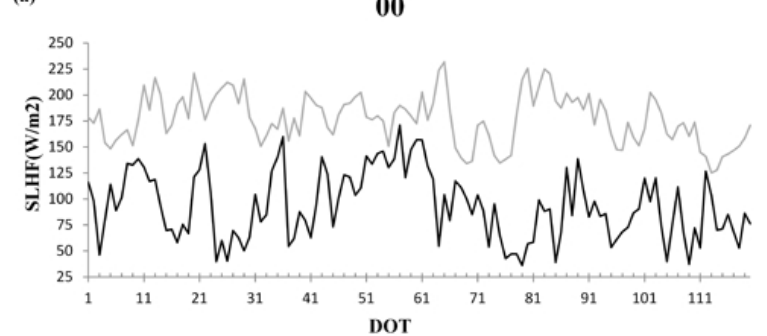

(c)

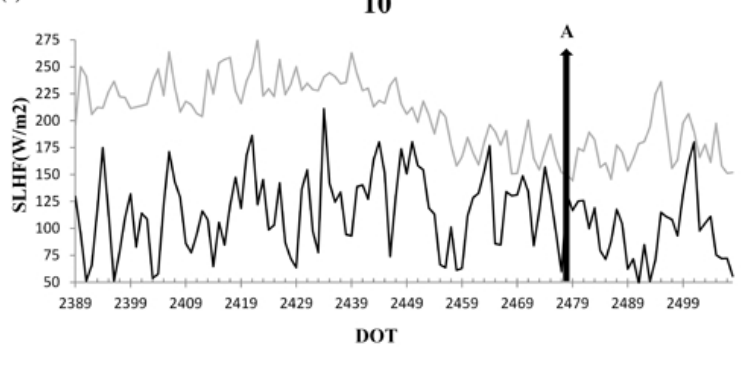

(b)

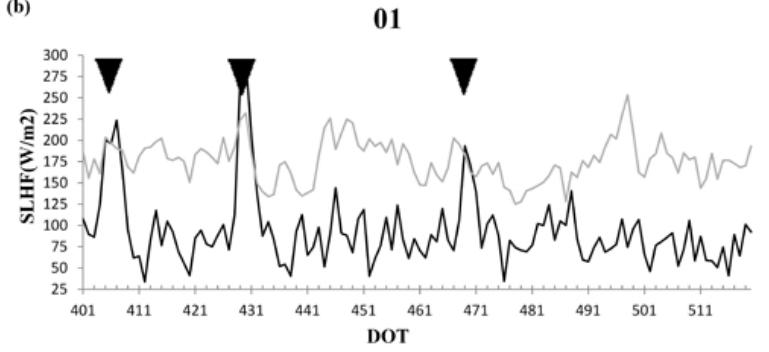

(d)

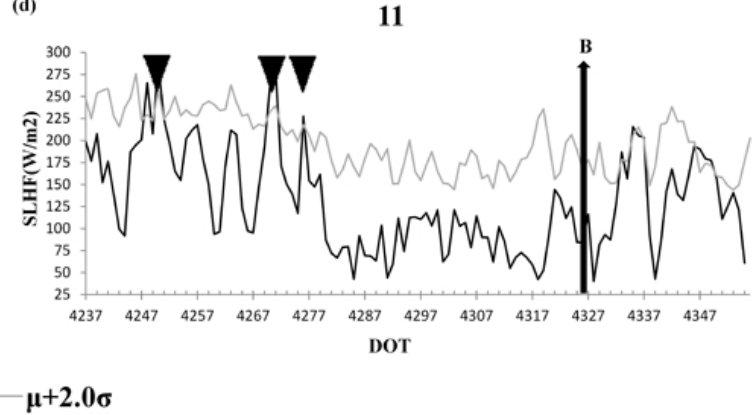

Fig. 2. The four types of relationships between SLHF anomalies and earthquakes.

years, including the study period, plus 2.0 times the standard deviation (i.e., $\mu+2.0 \sigma$ ).

Thirdly, considering the various geological and climatic backgrounds of the six earthquakes considered here, the values of time window, $\triangle \mathrm{DOT}$ and $E$ were established based on the short-term SLHF variations corresponding to each earthquake. The variation in SLHF for 90 days prior to and 30 days following each main shock is displayed in Fig. 3. The upper gray line shows the reference maximum values (i.e., anomaly thresholds). The lower black line represents the daily values of NCEP SLHF grid points encompassing the epicenter of each earthquake. The bold black arrow indicates the date of each earthquake and the triangle highlights SLHF anomalies. For the Sumatra earthquake, there was only one anomaly 69 days before the main shock. This anomaly lasted for 6 days and had an average value of $22.79 \mathrm{~W} \mathrm{~m}^{-2}$. Compared to the anomaly before the Sumatra earthquake, the anomaly associated with the ESSI earthquake was less significant; it lasted only 2 days and had a mean value of $7.77 \mathrm{~W} \mathrm{~m}^{-2}$. However, given the amplitude of the SLHF variations in the ESSI area, this anomaly is still notable. The two anomalies before the Papua earthquake are difficult to identify, and both have low $\triangle \mathrm{DOT}$ and abnormal ranges. Interestingly, an anomaly occurred 7 days after the main shock, which was near the peak value for the 3 months surrounding the main shock. However, we only focus on precursory SLHF anomalies and do not discuss this anomaly further. Seventy days prior to the Samoa earthquake, there was one obvious anomaly that continued into the next day and averaged $18.04 \mathrm{~W} \mathrm{~m}^{-2}$, which is relatively significant. Two peaks occurred before the Haiti earthquake, but they are both small. Three peaks exceed the background level before the Tohoku
Table 3. Four selected parameters of six earthquakes.

\begin{tabular}{lrrrr}
\hline Name & $M\left(M_{\mathrm{w}}\right)$ & $\begin{array}{r}\text { Anomaly } \\
\text { threshold }\end{array}$ & $\begin{array}{r}\text { Time } \\
\text { window }\end{array}$ & $\begin{array}{r}E \\
\left(\mathrm{~W} \mathrm{~m}^{-2}\right)\end{array}$ \\
\hline Sumatra & & & 70 & 22.79 \\
ESSI & & & 80 & 7.77 \\
Papua & & & 70 & 8.80 \\
Samoa & 5.0 & $\mu+2.0 \sigma$ & 70 & 18.04 \\
Haiti & & & 20 & 11.48 \\
Tohoku & & & 90 & 30.55 \\
\hline
\end{tabular}

earthquake. The mean values of these anomalies are larger than $30 \mathrm{~W} \mathrm{~m}^{-2}$, exceeding its $\mu+2.0 \sigma$ threshold by nearly $200 \%$. For each main shock, the values of time window and $\triangle \mathrm{DOT}$ are the maximum, while $\mathrm{E}$ is the average of anomaly values. Individual values of the four parameters for each studied earthquake can be found in Table 3 .

\subsection{Identification and long-term evaluation}

Based on the parameters established earlier in this paper, the long-term analysis for related SLHF variations and seismicity was carried out in two stages of comparison: " 01 " vs. " 11 " and " 10 " vs. " 11 ".

In the first stage, we computed the occurrence probability of " 01 " and " 11 ", i.e., we calculated the number of times that precursory changes in SLHF satisfied the standards of being an anomaly and the probability of earthquakes that occurred within the given time window. The variations in SLHF within one NCEP grid cell might be affected by several factors, including seasonal changes, monsoons, and seismic activity. To 

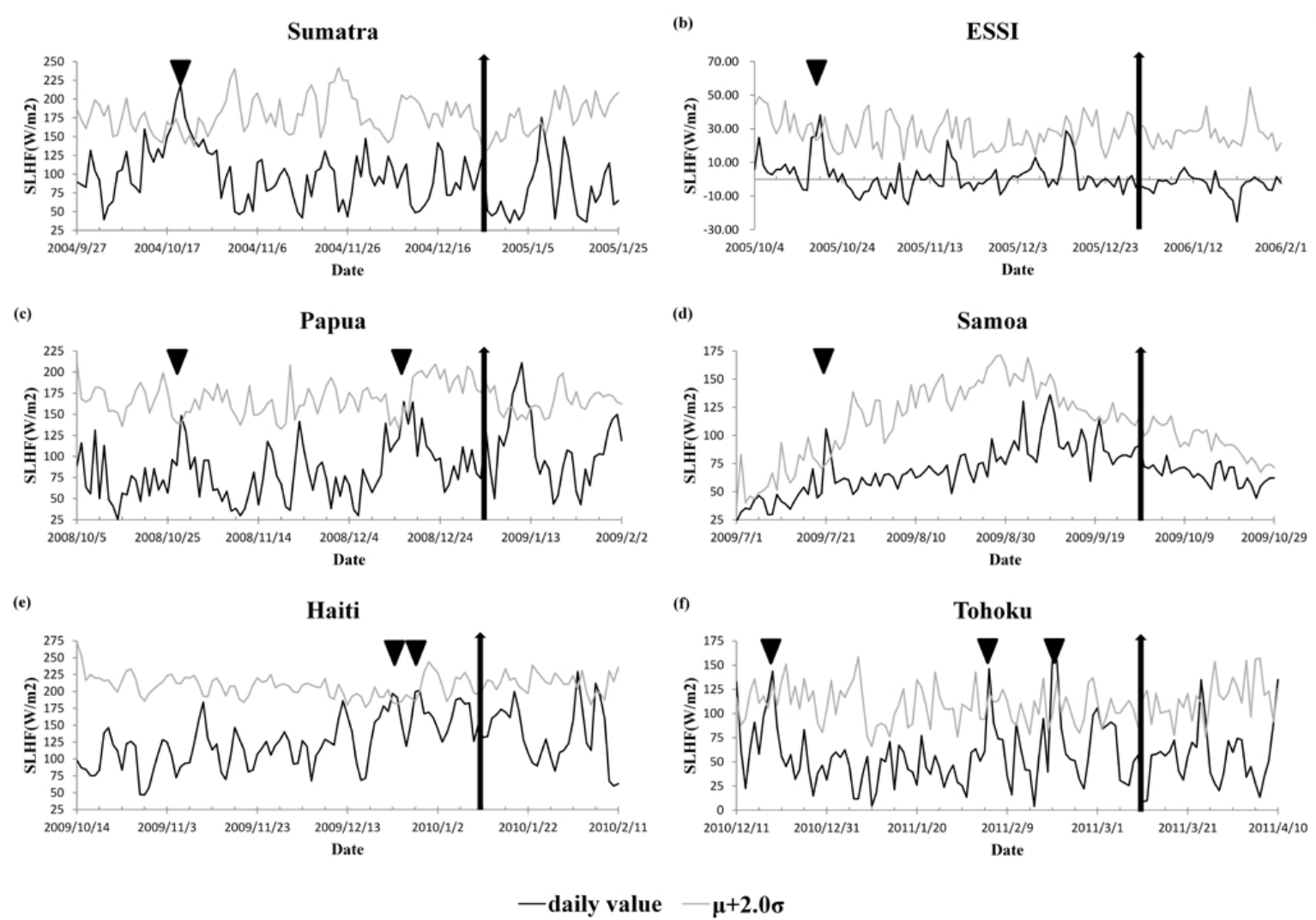

Fig. 3. SLHF variations for the six earthquakes.

assess the impact of earthquakes near the epicentral NCEP grid area, all earthquakes larger than a given magnitude $(M)$ and within an area of approximately 1 million $\mathrm{km}^{2}$ around the epicenter of each of the six earthquakes (roughly $10^{\circ}$ longitude by $10^{\circ}$ latitude; the individual area varies with the latitude of each epicenter) were taken into consideration. The results of this analysis are given in Table 4 . To remove the foreshock-main shock-aftershock effect and its influence on later changes in SLHF, we also combined earthquakes within 30 days of each other (referred to as solo earthquakes).

Table 4 gives the probabilities of " 01 " and " 11 " scenarios of relationships between SLHF anomalies and earthquakes. There are many instances in which the SLHF value surpassed the anomaly threshold. Haiti had the fewest anomalies. Even so, it had 42 abnormal variations over the past $20 \mathrm{yr}$. Before the removal of the earthquake clustering effect, the numbers of earthquakes larger than $M$ for each of the six cases were remarkable large. Except for Haiti, the percentages of " 11 " scenarios were significant, indicating that many earthquakes occurred after SLHF anomalies. After the de-clustering process, both the number of earthquakes and the percentage of "11" scenarios decreased significantly, and the correlation is statistically insignificant (see Table 5). Comparing the average surpassing values of SLHF variations, which were without a related earthquake to the anomalies prior to these earthquakes (i.e., "01"), shows that the anomalous peaks before the ESSI, Samoa and Haiti earthquakes are numerically insignificant. The values of $E$ for ESSI, Samoa and Haiti in the short term were successively 7.77, 18.04 and 11.48 , while in the long term were 9.57, 26.17 and 17.04. In other words, these SLHF fluctuations at such degrees may be very normal for these areas.

In the second stage of comparison, the probabilities of "10" and corresponding " 11 " scenarios were assessed. Instead of considering the seismicity in a $10^{\circ}$ by $10^{\circ}$ area surrounding each of the six epicenters, we focused on the earthquakes within the NCEP grid cell containing each epicenter. For each of the six earthquakes, an individual set of seismic events in the preceding $20 \mathrm{yr}$ was constructed. The percentages of SLHF anomalies that were within the specified time window before the earthquakes are given in Table 6 . Due to the SLHF data giving only daily mean values, any earthquakes that occurred on the same day were merged into one event to prevent duplicate computations. For the ESSI case, the number of earthquakes was small while the number of anomalies was relatively very large. It is interesting that there were not any anomalies that correspond with those three earthquakes in time sequence. Except for the Haiti case in which all of those anomalies occurred within its specific time window of that certain earthquake, the probabilities of 
Table 4. Probabilities of " 01 " and " 11 ".

\begin{tabular}{|c|c|c|c|c|c|c|}
\hline Name & Study period & Study area & No. of AN & No. of EQ & “01”\% & $" 11 " \%$ \\
\hline Sumatra & 1984/01/01-2003/12/31 & $\begin{array}{l}2^{\circ} \mathrm{S}-8^{\circ} \mathrm{N} \\
90-100^{\circ} \mathrm{E}\end{array}$ & 81 & 251 & $22.2 \%$ & $77.8 \%$ \\
\hline ESSI & 1985/01/01-2004/12/31 & $\begin{array}{l}56-66^{\circ} \mathrm{S} \\
17-27^{\circ} \mathrm{W}\end{array}$ & 100 & 375 & $12.0 \%$ & $88.0 \%$ \\
\hline Papua & 1984/01/01-2003/12/31 & $\begin{array}{l}5^{\circ} \mathrm{S}-5^{\circ} \mathrm{N} \\
127-137^{\circ} \mathrm{E}\end{array}$ & 77 & 61 & $56.0 \%$ & $44.0 \%$ \\
\hline Samoa & 1989/01/01-2008/12/31 & $\begin{array}{l}10-20^{\circ} \mathrm{S} \\
167-177^{\circ} \mathrm{W}\end{array}$ & 86 & 866 & $9.3 \%$ & $90.7 \%$ \\
\hline Haiti & $1989 / 01 / 01-2008 / 12 / 31$ & $\begin{array}{l}13-23^{\circ} \mathrm{N}, \\
67-77^{\circ} \mathrm{W}\end{array}$ & 42 & 31 & $92.9 \%$ & $7.1 \%$ \\
\hline Tohoku & 1990/01/01-2009/12/31 & $\begin{array}{l}33-43^{\circ} \mathrm{N}, \\
137-147^{\circ} \mathrm{E}\end{array}$ & 149 & 998 & $2.7 \%$ & $97.3 \%$ \\
\hline
\end{tabular}

* EQ: earthquake; AN: anomaly.

"11" for the Sumatra, Papua and Tohoku cases were less than $50 \%$. In the area surrounding the Samoa earthquake epicenter, 12 earthquakes occurred during the study period, while half of the earthquakes occurred after SLHF anomalies. In other words, for all earthquakes other than the Samoa and ESSI case, the percentages of "10" scenarios were distinctly higher than their counterparts, i.e., most of the earthquakes were not sensitive to variations in SLHF, even in the very near vicinity. What should be paid attention is that the average magnitudes of earthquakes that belonged to " 10 " for five cases were all more than $M_{\mathrm{W}}=5.3$.

\section{Discussion}

\subsection{Data applicability}

Although the use of a homogeneous data set (i.e., NCEPSLHF) would have alleviated the error due to different SLHF observations, the NCEP data set contains assimilative data whose accuracy relies on several factors. The accuracy of a single variable at different periods varies depending on the original data collection method. Although the NCEP reanalysis data assimilation system is consistent, the observing system has evolved substantially over time. The evolution of the global observing system is divided into three major phases: the "early" period from the 1940s through the International Geophysical Year in 1957, when the first upper-air observations were made; the "modern rawinsonde network" from 1958 to 1978 ; and the "modern satellite era" from 1979 to the present (Kalnay et al., 1996).

Therefore, the accuracy of reanalyzed surface latent heat fluxes is naturally time-dependent. Given the evolution of data accuracy, the SLHF anomalies preceding the ESSI, Papua and Haiti earthquakes were measured using less accurate NCEP SLHF data, i.e., $10-30 \mathrm{~W} \mathrm{~m}^{-2}$ accuracy. Therefore, these variations may not be true anomalies. Because the history of NCEP data is very short compared with the earthquake catalog, the date of a given earthquake should be considered before employing the NCEP/NCAR data in the study of SLHF variations prior to earthquakes. The output variables in NCEP/NCAR data are classified into four classes, depending on the degree to which they are influenced by the observational data and/or the assimilation model. Unfortunately, surface fluxes are among the "C" variables, which means that they depend heavily on the model during data assimilation (subject to the assimilation of other observations) and should be used with caution (Kistler et al., 2001). If the model and its physical parameterizations are realistic, the SLHF data can provide accurate estimates, even on a daily timescale. However, it will be regionally biased if the model is biased. Hence, the model feasibility should be checked before using SLHF data from NCEP/NCAR to study any SLHF variations in a specific area.

Several scientists have misused NCEP/NCAR data when studying the relationships between SLHF variations and seismicity. To correctly identify and detect direct or indirect earthquake-induced changes in SLHF using NCEP SLHF data, we suggest that long-term analysis be carried out for the study area to establish the background levels and check if any variations in them correlate with the SLHF changes and earthquakes.

\subsection{Parameter settings}

Like other thermal precursors, despite of several years of intense work focusing on the application of SLHF data to the prediction of coastal earthquakes, obvious precursor anomalies are generally found retrospectively after the events. To find these anomalies the evaluation criteria might be determined retroactively or adjusted, and there are no established and accepted parameters.

The anomaly threshold is the most important parameter to establish. When Dey and Singh proposed a probable relationship between SLHF anomalies and earthquakes, they 
Table 5. Probabilities of " 01 " and " 11 " after declustering.

\begin{tabular}{lrrrrrr}
\hline Name & Sumatra & ESSI & Papua & Samoa & Haiti & Tohoku \\
\hline No. of solo EQ & 37 & 31 & 28 & 3 & 22 & 4 \\
"01" \% & $67.9 \%$ & $66.0 \%$ & $74.0 \%$ & $95.3 \%$ & $95.2 \%$ & $95.3 \%$ \\
"11"\% & $32.1 \%$ & $34.0 \%$ & $26.0 \%$ & $4.7 \%$ & $4.8 \%$ & $4.7 \%$ \\
Ave. surpass value $\left(\mathrm{W} \mathrm{m}^{-2}\right)$ & 19.39 & 9.57 & 20.21 & 26.17 & 17.04 & 23.75 \\
\hline
\end{tabular}

*EQ: earthquake; AN: anomaly.

Table 6. Probabilities of " 10 " and " 11 ".

\begin{tabular}{|c|c|c|c|c|c|c|c|}
\hline Name & Study period & Study area & No. of EQ & No. of AN & $" 10 " \%$ & $" 11 " \%$ & $M\left(M_{\mathrm{W}}\right)$ \\
\hline Sumatra & 1984/01/01-2003/12/31 & $\begin{array}{l}2.875-4.761^{\circ} \mathrm{N} \\
95.625-97.5^{\circ} \mathrm{E}\end{array}$ & 37 & 89 & $59.5 \%$ & $40.5 \%$ & 5.42 \\
\hline ESSI & 1985/01/01-2004/12/31 & $\begin{array}{l}59.998-61.903^{\circ} \mathrm{S} \\
20.625-55.2^{\circ} \mathrm{W}\end{array}$ & 3 & 107 & $100 \%$ & 0 & 5.57 \\
\hline Papua & 1984/01/01-2003/12/31 & $\begin{array}{l}0.952^{\circ} \mathrm{S}-0.952^{\circ} \mathrm{N} \\
131.25-133.13^{\circ} \mathrm{E}\end{array}$ & 16 & 96 & $62.5 \%$ & $37.5 \%$ & 5.36 \\
\hline Samoa & 1989/01/01-2008/12/31 & $\begin{array}{l}14.285-16.19^{\circ} \mathrm{S}, \\
170.625-172.5^{\circ} \mathrm{W}\end{array}$ & 12 & 93 & $50 \%$ & $50 \%$ & 5.38 \\
\hline Haiti & 1989/01/01-2008/12/31 & $\begin{array}{l}18.094-19.999^{\circ} \mathrm{N} \\
71.25-73.125^{\circ} \mathrm{W}\end{array}$ & 1 & 45 & 0 & $100 \%$ & - \\
\hline Tohoku & 1990/01/01-2009/12/31 & $\begin{array}{l}37.142-39.047^{\circ} \mathrm{N} \\
140.625-142.5^{\circ} \mathrm{E}\end{array}$ & 69 & 48 & $56.5 \%$ & $43.5 \%$ & 5.50 \\
\hline
\end{tabular}

* EQ: earthquake; AN: anomaly.

accounted for seasonal effects by subtracting the monthly mean from the daily value and dividing the daily SLHF value by the standard deviation of the SLHF data for that specific day within each year from a $10 \mathrm{yr}$ data set. The background noise was calculated as the mean SLHF plus 1.5 times the standard deviation of SLHF (Dey and Singh, 2003). Other analogous thresholds have been given by other scientists, such as $\mu+\sigma$ (Li et al., 2008; Pulinets et al., 2006) or $\mu+2.0 \sigma$ (Qin et al., 2010). SLHF fluctuations occur continuously in any area. Daily SLHF values in a given area over several years results in a large data set that conforms to a normal distribution. According to the well-known 68-9599.7 rule (three sigma rule), only approximately $86.6 \%$ of values are within $\mu \pm 1.5 \sigma$ (Larson and Farber, 2009). The remaining $13.4 \%$ of the SLHF anomalies might be regular fluctuations due to seasonal factors and not seismicity. As Henk Tijms said, "the theory of probabilities ... teaches us to avoid the illusions which often mislead us" (Tijms, 2004). Keeping the concept of normal distributions in mind may assist in determining the validity of seismic precursors. The conditions used to determine whether a specific variation in SLHF is anomalous behavior is one of the key issues in the study of correlations between SLHF and earthquakes. Methodical detection of SLHF anomalies should be achieved when investigating the relationship between SLHF variations and earthquakes.
The time window is also fundamental to the correlation evaluation. Individual time windows for six cases were fixed according to the short-term SLHF variations. In fact, there is no known way to determine this parameter other than empirically. It might vary with the earthquake location, time and other related factors. To determine how the time window affects the calculated correlation between SLHF anomalies and earthquakes, we set 10 time windows (of 90, 80, 70, 60, 50, $40,30,20,10$ and 5 days) and computed the proportions of " 01 " and "10" scenarios for each window. Figure 4a illustrates the negative correlation between time window and the proportion of " 01 " scenarios. For a time window of 5 days, the proportions of all the six cases was 1, i.e., almost no earthquakes occurred within 5 days of each anomaly. Figure $4 \mathrm{~b}$ shows the SLHF anomaly that occurred 5-10 days before the Haiti earthquake. For the ESSI earthquake, the percentage of " 10 " scenarios is $100 \%$ for all of these time windows, which indicates that 107 anomalies occurred more than 90 days before the three qualified earthquakes. For the other four earthquakes, the proportions decreased with longer time windows. As shown in Fig. 4, the correlation between thermal anomalies and seismicity is highly dependent on the length of the time window. The longer time window is set, the more thermal anomalies can be considered precursors of a specific earthquake. Therefore, the percentage of " 11 " scenarios increases with longer time windows and causes precursory activity to appear more likely. 

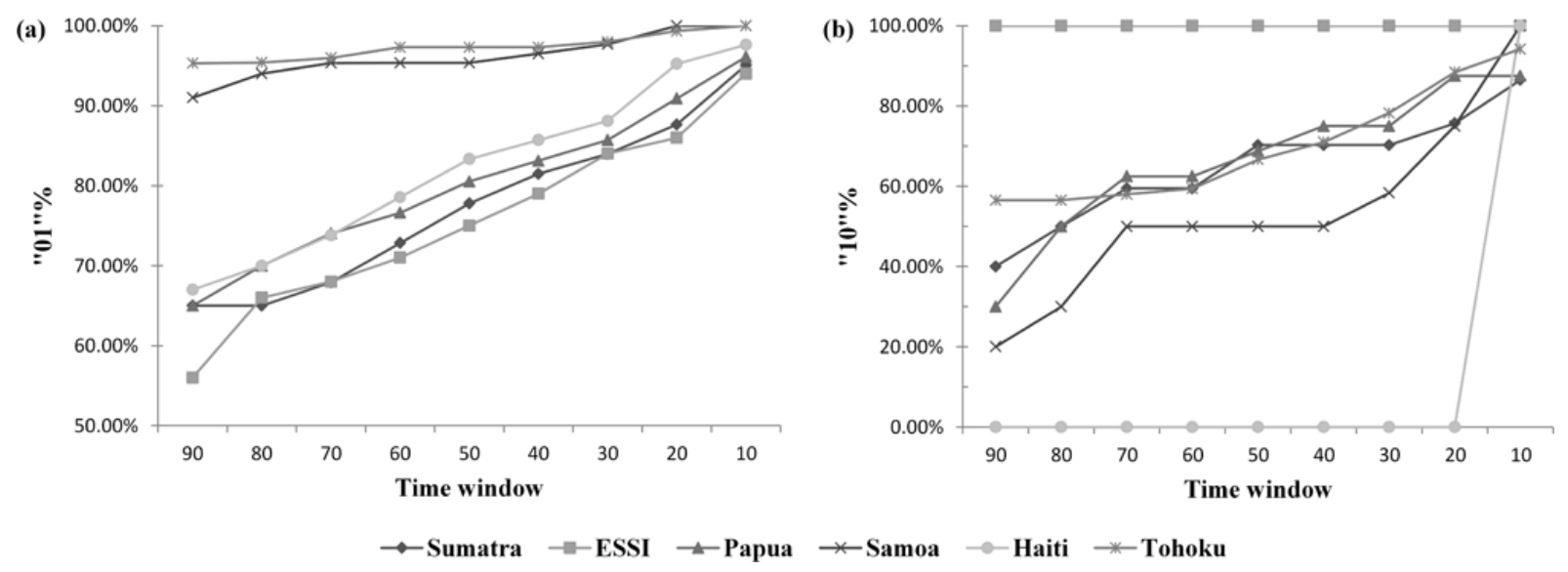

Fig. 4. The relationship between the time window and percentages of " 01 " and " 10 " scenarios.

\section{Summary and conclusion}

In light of these evaluation results obtained from this study, several conclusions can be drawn: (1) although some SLHF variations may surpass the background varying level, they still cannot be recognized as thermal anomalies according to their tiny surpassing amplitudes and SLHF data accuracy; (2) the clustering effect of earthquake sequence should be paid enough attention during the evaluation of relationship between SLHF variations and earthquakes; (3) the correlation of SLHF anomalies and seismic activity is relatively low (due to chance) and largely depends on several factors including data and parameters.

We strongly recommend that standard SLHF anomaly detecting criteria should be established. While several adjustments to parameters at the learning stage are acceptable, one must ensure that the corresponding criteria have been clearly set and strictly employed before any phenomenon is formally defined as a precursor. Even if the geophysical theory is not understood thoroughly, predetermined identifying and analyzing procedures still need to be taken into account and addressed.

Based on the above findings, much further work can be effectively carried out. We will perform more evaluations on several other related thermal parameters that are derived by remote sensing or assimilation technology. Other related factors including the seasonal variations in wind and ocean current, regional salinity concentration and relative humidity will be taken into account. Moreover, keeping the advantage of remote sensing data in spatial resolution in mind, further long-term spatial analysis for the mentioned earthquakes will be carried out. Similar to one single NCEP grid analysis, parameters such as time window and anomaly threshold will be selected to study the spatial and temporal relationship between earthquakes and thermal variations. More data mining technologies will also contribute to the following work.
Acknowledgements. The NCEP Reanalysis data were provided by the NOAA/OAR/ESRL PSD, Boulder, Colorado, USA, from their web site at http://www.esrl.noaa.gov/psd/. This work is supported by the National Natural Science Foundation of China Grant Nos. 41171265 and 40801131, and the National High-Tech Research and Development Plan of China Grant No. 2010AA122202. This work is also funded by a major project of the State Key Laboratory of Remote Sensing Science of China and the open foundation of Guangxi Key Laboratory of Spatial Information and Geomantics, grant nos 1103108-04 and 1103108-09. The authors would like to thank three reviewers and Editor A. Kopf for their valuable suggestions that have greatly improved this paper. The authors would also like to thank Xiaowen Li for his enlightment at the very beginning of this research.

Edited by: A. Kopf

Reviewed by: R. Geller and two anonymous referees

\section{References}

Bourras, D.: Comparison of five satellite-derived latent heat flux products to moored buoy data, J. Climate, 19, 6291-6313, doi:10.1175/JCLI3977.1, 2006.

Cervone, G., Kafatos, M., Napoletani, D., and Singh, R. P.: Wavelet maxima curves of surface latent heat flux associated with two recent Greek earthquakes, Nat. Hazards Earth Syst. Sci., 4, 359374, doi:10.5194/nhess-4-359-2004, 2004.

Cervone, G., Singh, R. P., Kafatos, M., and Yu, C.: Wavelet maxima curves of surface latent heat flux anomalies associated with Indian earthquakes, Nat. Hazards Earth Syst. Sci., 5, 87-99, doi:10.5194/nhess-5-87-2005, 2005.

Chen, M., Deng, Z., Yang, Z., and Ma, X.: Surface latent heat flux anomalies prior to the indonesia Mw9.0 earthquake of 2004, Chinese Sci. Bull., 51, 1010-1013, doi:10.1007/s11434-006-1010-y, 2006.

Choudhury, S., Dasgupta, S., Saraf, A. K., and Panda, S.: Remote sensing observations of pre-earthquake thermal anomalies in Iran, Int. J. Remote Sens., 27, 4381-4396, doi:10.1080/01431160600851827, 2006. 
Dey, S. and Singh, R. P.: Surface latent heat flux as an earthquake precursor, Nat. Hazards Earth Syst. Sci., 3, 749-755, doi:10.5194/nhess-3-749-2003, 2003.

Freund, F. T., Takeuchi, A., Lau, B. W. S., Al-Manaseer, A., Fu, C. C., Bryant, N. A., and Ouzounov, D.: Stimulated infrared emission from rocks: assessing a stress indicator, eEarth, 2, 7-16, doi:10.5194/ee-2-7-2007, 2007.

Geller, R. J.: Earthquake prediction: a critical review, Geophys. J. Int., 131, 425-450, doi:10.1111/j.1365-246X.1997.tb06588.x, 1997.

Genzano, N., Aliano, C., Filizzola, C., Pergola, N., and Tramutoli, V.: A robust satellite technique for monitoring seismically active areas: The case of Bhuj-Gujarat earthquake, Tectonophysics, 431, 197-210, doi:10.1016/j.tecto.2006.04.024, 2007.

Hao, S., Gao, H., and Wang, C.: Isothermal surface of Curie temperature around the Beijing area and its relation to earthquakes, Acta Geophys. Sinica, 25, 264-269, 1982.

Jackson, D. D.: Hypothesis testing and earthquake prediction, Proc. Natli. Acad. Sci., 93, 3772-3775, doi:10.1073/pnas.93.9.3772, 1996.

Kagan, Y. Y.: Are earthquake predictable, Geophys. J. Int., 131, 505-525, doi:10.1111/j.1365-246X.1997.tb06595, 1997.

Kagan, Y. Y. and Jackson, D. D.: Statistical tests of VAN earthquake predictions comments and reflections, Geophys. Res. Lett., 23, 1433-1436, doi:10.1029/95GL03786, 1996.

2. Kalnay, E., Kanamitsu, M., Kistler, R., Collins, W., Deaven, D., Gandin, L., Iredell, M., Saha, S., White, G., Woollen, J., Zhu, Y., Leetmaa, A., Reynolds, R., Chelliah, M., Ebisuzaki, W., Higgins, W., Janowiak, J., Mo, K. C., Ropelewski, C., Wang, J., Jenne, R., and Joseph, D.: The NCEP/NCAR 40-year reanalysis project, B. Am. Meteorol. Soc., 77, 437-471, doi:10.1175/15200477(1996)077<0437:TNYRP>2.0.CO;2, 1996.

Kistler, R., Collins, W., Saha, S., White, G., Woollen, J., Kalnay, E., Chelliah, M., Ebisuzaki , W., Kanamitsu , M., Kousky , V., Dool, H., Jenne, R., and Fiorino, M.: The NCEP-NCAR 50-year reanalysis: monthly means CD-ROM and documentation, B. Am. Meteorol. Soc., 82, 247-268, doi:10.1175/15200477(2001)082<0247:TNNYRM>2.3.CO;2, 2001.

Larson, R. and Farber, E.: Elementary statistics: picturing the world, Pearson Prentice Hall, Upper Saddle River, NJ, 2009.

Li, J., Wu, L., Wen, Z., and Liu, S.: Studies on abnormal surface latent heat flux prior to major coastal and terrestrial earthquake in China, Rev. Sci. Technol., 26, 40-45, 1000-7857(2008)05-004006, 2008.

Ouzounov, D. and Freund, F.: Mid-infrared emission prior to strong earthquakes analyzed by remote sensing data, Adv. Space Res., 3, 268-273, doi:10.1016/S0273-1177(03)00486-1, 2004.

Ouzounov, D., Liu, D., Kang, C., Cervone, G., Kafatos, M., and Taylor, P.: Outgoing long wave radiation variability from IR satellite data prior to major earthquakes, Tectonophysics, 431, 211-220, doi:10.1016/j.tecto.2006.05.042, 2007.
Pulinets, S. A., Ouzounov, D., Ciraolo, L., Singh, R., Cervone, G., Leyva, A., Dunajecka, M., Karelin, A. V., Boyarchuk, K. A., and Kotsarenko, A.: Thermal, atmospheric and ionospheric anomalies around the time of the Colima M7.8 earthquake of 21 January 2003, Ann. Geophys., 24, 835-849, doi:10.5194/angeo-24-8352006, 2006.

Qiang, Z., Gong, L., Zheng, L., Guo, M., Wang, G., and Zhao, Y.: An experimental study on temperature increasing mechanism of satellite thermo-infrared, Seismol. Soc. China, 10, 247-252, doi:10.1007/s11589-997-0093-0, 1997.

Qin, K., Wang, B., Guo, G., and Yang, J.: Analysis thermal anomaly preceding Xinjiang earthquake using NCEP data, J. Jilin University (Earth Science Edition), 6, 1075-1080, 1671-5888(2008)061075-06, 2008.

Qin, K., Wu, L., and Ma, W.: Spatial-temporal features of abnormal surface latent heat flux before the Qinghai Haixi earthquake sequence in 2009, Rev. Scie. Technol., 28, 68-73, doi:10007857(2010)04-0068-06, 2010.

Saraf, A. K., Rawat, V., Choudhury, S., Dasgupta, S., and Das, J.: Advances in understanding of the mechanism for generation of earthquake thermal precursors detected by satellites, Int. J. Appl. Earth Observation Geoinf., 11, 373-379, doi:10.1016/j.jag.2009.07.003, 2009.

Schulz, J., Meywerk, J., Ewald, S., and Schlüssel, P.: Evaluation of satellite-derived latent heat fluxes, J. Climate, 10, 2782-2795, doi:10.1175/1520-0442(1997)010<2782:EOSDLH>2.0.CO;2, 1997.

Singh, R. P., Simon, B., and Joshi, P. C.: Estimation of surface latent heat fluxes from IRS-P4/MSMR satellite data, J. Earth Syst. Sci., 110, 231-238, doi:10.1007/BF02702238, 2001.

Singh, R. P., Cervone, G., Singh, V. P., and Kafatos, M.: Generic precursors to coastal earthquakes: Inferences from Denali fault earthquake, Tectonophysics, 431, 231-240, doi:10.1016/j.tecto.2006.05.040, 2007.

Tijms, H.: Understanding probability: chance rules in everyday life, Cambridge University Press, Cambridge, 2007.

Tronin, A.: Satellite thermal survey - a new tool for the study of seismoactive regions, Int. J. Remote Sens., 17, 1439-1455, doi:10.1080/01431169608948716, 1996.

Tronin, A.: Thermal IR satellite sensor data application for earthquake research in China, Int. J. Remote Sens., 16, 3169-3177, doi:10.1080/01431160050145054, 2000.

Wang, L. and Zhu, C.: Anomalous variations of ground temperature before the Tangshan and Haicheng earthquakes, J. Seismol. Res., 7, 649-656, 1984.

Zhang, Y., Guo, X., Zhong, M., Shen, W., Li, W., and He, B.: Wenchuan earthquake:Brightness temperature changes from satellite infrared information, Chinese Sci. Bull., 55, 1917-1924, doi:10.1007/s11434-010-3016-8, 2010. 